University at Albany, State University of New York

Scholars Archive

2-2005

\title{
Peirce: Underdetermination, agnosticism, and related mistakes
}

P.D. Magnus

University at Albany, State University of New York, pmagnus@albany.edu

Follow this and additional works at: https://scholarsarchive.library.albany.edu/cas_philosophy_scholar

Part of the Philosophy Commons

\section{Recommended Citation}

Magnus, P.D., "Peirce: Underdetermination, agnosticism, and related mistakes" (2005). Philosophy Faculty Scholarship. 28.

https://scholarsarchive.library.albany.edu/cas_philosophy_scholar/28

This Article is brought to you for free and open access by the Philosophy at Scholars Archive. It has been accepted for inclusion in Philosophy Faculty Scholarship by an authorized administrator of Scholars Archive. For more information, please contact scholarsarchive@albany.edu. 


\title{
Peirce: Underdetermination, agnosticism, and related mistakes
}

\author{
P.D. Magnus* \\ Inquiry, 48(1): 26-37. February 2005. \\ web: http://www.fecundity.com/job \\ e-mail: pmagnus(at)fecundity.com
}

\begin{abstract}
There are two ways that we might respond to the underdetermination of theory by data. One response, which we can call the agnostic response, is to suspend judgment: 'Where scientific standards cannot guide us, we should believe nothing.' Another response, which we can call the fideist response, is to believe whatever we would like to believe: 'If science cannot speak to the question, then we may believe anything without science ever contradicting us.' C.S. Peirce recognized these options and suggested evading the dilemma. It is a Logical Maxim, he suggests, that there could be no genuine underdetermination. This is no longer a viable option in the wake of developments in modern physics, so we must face the dilemma head on. The agnostic and fideist responses to underdetermination represent fundamentally different epistemic viewpoints. Nevertheless, the choice between them is not an unresolvable struggle between incommensurable worldviews. There are legitimate considerations tugging in each direction. Given the balance of these considerations, there should be a modest presumption of agnosticism. This may conflict with Peirce's Logical Maxim, but it preserves all that we can preserve of the Peircean motivation.
\end{abstract}

1. Peirce's Logical Maxim

2. The concept of underdetermination

3. Our dilemma

4. Endgame

* My understanding of Peirce was nurtured by conversations at the University of California, San Diego, through a succession of pragmatist reading groups. I am indebted to all the participants in those groups, especially David Smith, Ilya Farber, and Naomi Oreskes. $\S 3$ of the present paper is based on $\S 1.3 .3$ of my [Mag03]. 
The underdetermination of theory by data is often taken to guarantee that some questions cannot be answered by any amount of enquiry. Underdetermination of this kind would confront us with a dilemma: Either we remain forever and inexorably agnostic about the underdetermined questions or we apportion our beliefs by fiat. C.S. Peirce recognized this dilemma, and we can use his answer to it as a way of framing the problem. Peirce thought neither horn of the dilemma was acceptable, so he suggested that there could be no underdetermination of this kind.

\section{Peirce's Logical Maxim}

In the manuscript written for his fourth lecture at Harvard in 1903, Peirce claims that - as a matter of logic - we must never say that some questions could never be answered. As we might say today, he denies that there could be any underdetermination. (Contemporary discussions of underdetermination often take Poincaré or Duhem as their starting point; Peirce here explicitly takes issue with Poincaré.) "Let me recommend this Logical Maxim to you," he writes, "Never allow yourself to think that any definite problem is incapable of being solved to any assignable degree of perfection" [Pei97, p. 273]. ${ }^{1}$ Peirce worries: If we do think that there is underdetermination, then we will either make the error of agnosticism or the related mistake of "simply accept[ing] what opinions suit our fancy or convenience, or seem likely to advance our interests" [Pei97, p. 273]. This latter mistake of believing whatever is convenient is the sort of vulgarity for which pragmatists have too often been condemned, but Peirce thinks it is "the prevalent [mistake] in regard to philosophy, the world over."

Peirce suggests that matters which are presumed insoluble will be resolved quickly enough when "the right distinction" is introduced [Pei97, p. 273]. If you think some matter is insoluble, he writes:

The likelihood is that it will be solved long before you could have dreamed possible. Think of Auguste Comte who when asked to name any thing that could never be found out instanced the chemical composition of the fixed stars; and almost before his book became known to the world at large, the first steps had been taken in spectral analysis. [Pei97, p. 273]

Peirce thinks that the Logical Maxim can be given an "historical induction" with examples of this kind. Start with the example of Comte, who wrongly thought that theories of stellar composition were underdetermined. If we look around, Peirce suggests, we will see that alleged underdetermination has always or often been resolved in the course of enquiry.

Peirce also thinks that the Logical Maxim admits of stronger demonstration. "It rests," he says, "on the consideration of the nature of reasoning ...[and]... experimentation" [Pei97, p. 274]. Underdetermination would thus be inimical to 
the very nature of experimental method. Unfortunately, he says nothing further in the manuscript to suggest what this consideration is supposed to be.

We should be less sanguine about the verdict of an historical induction and considerations of experimental reasoning. Given developments since Peirce's time, we have been led by reasoning and experiment to accept quantum mechanics and relativity. Each entails limits to enquiry that resist dissolution by "the right distinction." According to many interpretations of quantum mechanics, the theory posits states of the world that we cannot discover beyond some knowable degree of precision. General relativity is even more striking; it entails that the structure of spacetime can preclude our learning certain important facts about the world [Gly77] [Mal77]. It seems as if it must be impossible to have a causal influence on our own past, for example, but relativity entails that - if it were impossible - the structure of spacetime would make it impossible for any observer to know this [Mal77, pp. 71-2]. If it were possible to influence our own past, then it might be possible to know this. Nevertheless, physicists do not allow logic to dictate whether such closed causal curves exist. Here in history and practice, physicists have not followed Peirce's Logical Maxim. One might say that physicists are wrong and that they should follow the Maxim, but one cannot then appeal to the history and practice of physics as support for the Logical Maxim itself.

So there is a prima facie conflict between modern physics and Peirce's Logical Maxim. In $\S 4.2$, I consider a different interpretation of the Maxim which could reconcile it with physics. For now, let's consider what we might do when faced with insolubilia. As Peirce notes, we would be forced into a dilemma between agnosticism and willy-nilly belief. So which should it be?

\section{The concept of underdetermination}

Before exploring the dilemma in the next section, I want to be clear about what 'underdetermination' means in this context. Plausibly, the term refers to cases where responsible theory choice would be impossible given any logically possible evidence - think of Cartesian sceptical scenarios in which 'everything is just as if there were an external world.' It is also natural to say that the choice between theories is underdetermined if it would be impossible to decide between them given the laws of nature - for instance, determination of the global structure of spacetime might require travelling faster than the speed of light (as in Glymour [Gly77] and Malament [Mal77], cited above). Other authors speak of 'transient underdetermination' that effects theory choice in early historical periods but not at later times (as in Sklar [Skl85] and Stanford [Sta01]). All of these involve an inability to decide between theories, but the inability is of different scope in each case.

As such, specifying a case of underdetermination involves specifying the range of possible circumstances across which responsible theory choice would be impossible. Call this range of circumstances the scope of the underdetermination. The choice between belief in an external world and belief in a Cartesian 
sceptical scenario, if it is underdetermined, is underdetermination with a scope that includes all logically possible circumstances. The global structure of spacetime is underdetermined with a scope that includes only nomologically possible circumstances. Transient cases will be underdetermined with a scope that includes earlier circumstances but not later ones. In general, we can entertain cases where the scope is any range of circumstances whatsoever. If the choice between rival theories cannot be made responsibly given any of the circumstances in the scope, then we can say that the theory choice is underdetermined with that scope. Menacing cases of underdetermination will be those for which our present circumstance is in the scope of the case (We can't responsibly distinguish between the theories now) and it would be hard or impossible for us to escape the scope (We can't change our circumstances so that we could distinguish between the theories).

A claim of underdetermination, then, is a claim that ordinary scientific considerations leave scientists no way to decide between competing theories in a certain range of circumstances. This implicitly relies on a conception of ordinary scientific considerations; that is, a standard for how scientists may responsibly decide between theories. Specifying a case of underdetermination thus requires specifying three things (at least implicitly): rival theories, a scope, and a standard. ${ }^{2}$

With these ideas in place, let's return to the dilemma.

\section{Our dilemma}

Cases of underdetermination with maximal scope- cases that could not be decided responsibly under any imaginable circumstances - elicit these two conflicting intuitions. The agnostic intuition is that, since the choice is forever beyond determination, one ought forever to suspend judgment about which of the rivals is true. The fideist intuition is that one might freely believe one of the rivals even now, since further enquiry will have no bearing on the question either way. The agnostic impulse is, in effect, to insist that the usual standard for responsible choice should hold even when it makes a theory choice undetermined with maximal scope; the only responsible thing to do in such cases is to be indifferent between the rivals. Contrarily, the fideist suggests that where a theory choice is underdetermined with maximal scope given the usual standard, one ought to suspend the usual standard in favor of the standard 'Believe what you will.' On this alternate standard, the choice need not be underdetermined.

The agnostic may try to provide a direct answer to the fideist by arguing that the usual standards are the unique standards of rationality. Scientific standards are historical products, however, and calling them rational does not show that they should apply under all circumstances. The fideist, after all, is arguing about what counts as reasonable.

As the terms are often used, 'agnosticism' and 'fideism' regard religious questions. Here I mean them to pick out views about how to respond to underdetermination in general - whether the enquiry is religious or secular. The 
agnostic approach is reflected in Descartes' reply to the sceptical scenarios and in much of the modern tradition. The fideist approach can be found in the writings inter alia of James [Jam48], Duhem [Duh54], and van Fraassen [van02], although I am overlooking certain subtleties in their views. For instance, James advocates fideism only for 'forced' and 'momentous' questions. This parallels the distinction Peirce sometimes draws between 'vital' questions and those which may be settled by rational enquiry. Regarding this complicated issue, see Hookway [Hoo02, esp. ch. 1]. For the sake of discussion here, I will sidestep it and consider the unqualified fideism that makes no such distinction.

\subsection{A test case: Other minds}

An example may help evoke these intuitions. Let the set of rivals contain one theory according to which you and most other human beings have minds and another according to which only you the reader have a mind and everyone else merely behaves as if they do. The rivalry between these two theories amounts to the familiar problem of other minds. It is arguably underdetermined with maximal scope, since the two rivals would lead us to expect exactly the same course of events in the world.

There is a sense in which fideism regarding this question could do no harm. If there were any negative repercussions from choosing the wrong theory, then there would be a circumstance in which you could decide the question: You could see in retrospect that the other one must have been preferable, and fallout from choosing poorly would provide a sort of experimental test. If the choice is underdetermined with a scope that includes all circumstances, such tests are precluded. So no harm could come from being a fideist.

Yet the fact that the theory choice has no practical consequences that could be used to test either theory does not entail that it has no practical consequences tout court. If you believe that you would have moral duties to people that you would not have to automatons, then there is a practical difference between the two. From one theory, it follows that you have a duty not to commit murder; from the other, it follows that murder is of a kind with smashing a television. Further experience will not contradict you in either case, but you may well act differently if you believe one rather than the other. How would you act if, taking the agnostic position, you remained indifferent between the two possibilities? How would you order your affairs if you lived with a real and persistent doubt as to whether other humans had mental lives like you have? It is tempting to think that you would become what the rest of us would call a sociopath. Sincere agnosticism about other minds, like solipsism, carries at least the hint of madness. Given your willingness to say that other people have experiences just as you do, doesn't it mean you are willing to relax your epistemic scruples on this matter?

If so, then the fideist wins the point. The agnostic may respond by arguing that the problem is not underdetermined. She may say: The madness of suspending judgement on this matter shows that the choice is not underdetermined even on ordinary standards, since any reasonable standard would allow 
you to choose the sane choice over the mad one. Philosophers have offered a panoply of reasons to believe in other minds rather than solipsism - readers are invited to consider their favorites. If such arguments are successful, then the case is not underdetermined. Thus, the agnostic may admit that there is an intuition about other minds while denying that the intuition speaks to the issue of underdetermination.

\subsection{The cost of fideism}

Moreover, the agnostic may insist, fideism could do unintended harm. Good querists realize that reflective and deliberate application of standards is not enough. They try to develop habits of applying the standards of responsible theory choice; they cultivate these inclinations, so that they would feel uncomfortable accepting claims for which no good reasons can be adduced. They also place themselves in a social order that enforces the standards for responsible theory choice, they willingly put themselves in a situation where they would be chastised for capricious belief. The fideist only deliberately suspends the usual standard when a theory choice is underdetermined with maximal scope, to be sure, but he must thus work to weaken his and the community's habitual application of the usual standard. Suppose that the choice between two theories is underdetermined with a maximal scope and that the fideist prefers to believe one rather than the other. If he ever has occasion to consider his choice, he will need to steel himself against his habituated unease; he will need to suppress the reaction which he cultivates in usual cases. Perhaps in reflective moments he will apply the usual standards as well as any querist. In more mundane moments, though, his habits will be weaker than those of the agnostics who spent no energy weakening theirs. There may well come a time when he will blunder where they might apply the usual standard by force of habit. ${ }^{3}$

The fideist might reply: It is an empirical question as to whether querists are best served by relying on brute habit. Perhaps for the bulk of enquiry and for the bulk of querists, for normal scientists doing normal science, this will be the case. Those who are of stronger character can distinguish between cases, however. They will recognize the differences between cases underdetermined with maximal scope where they may believe as they will and cases underdetermined with narrower scope. Why should such stronger types be held back from exercising their strong character?

The agnostic replies in turn: It is doubtful that anyone has such a strong character, but that is - as you say - an empirical matter. Even if some scientists do have such a character, they should not exercise it. As it is said: "Be careful that the exercise of your freedom does not become a stumbling block to the weak." [1Corinthians, 8:9]. Other scientists would either decide that they, too, could believe as they chose or be forced to admit that they had weak cognitive constitutions. If the former, then their habits would be weakened. If the latter, then they would be disheartened, and an unhealthy social division would be drawn among scientists. Thus if any scientists are such that their habits will be significantly eroded by fideism, then the whole community should embrace 
agnosticism.

The fideist replies, of course, but we can leave them to the dialogue. There are open questions of the degree to which habit formation is a good way to instill the usual standards of reasonable theory choice, the degree to which fideism would undercut these habits, and the degree to which fideism for a few would disrupt the community. These are questions which must be answered by further methodological reflection and psychological data.

\subsection{Fideism and narrower scope}

The fideist intuition is strongest in cases, like the alleged underdetermination about other minds, where the scope is maximal. The fideist may further wish to suspend the usual standards of responsibility for choices which are underdetermined with a narrower scope - for instance, a scope of all naturally possible circumstances as defined by some well-confirmed background theory. This would exacerbate the problem of poor habits, since choices which are subject to the usual standards may closely resemble ones which are exempted from those standards.

Consider that special relativity entails that an observer cannot be affected by events outside her past light cone. ${ }^{4}$ Supposing that she can only responsibly make theory choices on the basis of events to which she has some causal connection, specific claims about events outside her past light cone will be underdetermined for her with a scope constrained by what is possible given the laws of nature. Consider two events, call them $I$ and $O$. Suppose that $I$ was, from our observer's frame of reference, one thousand years in the past and 50 $\mathrm{cm}$ inside the surface of her past light cone and that $O$ was, again from the observer's frame of reference, simultaneous with $I$ but $50 \mathrm{~cm}$ outside the surface of her past light cone. (As in figure 1.)

[ Float figure 1 here. Caption: The observer may be effected now by $I$, but not by $O$, since the latter is outside the observer's past light cone. ]

Following the fideism here on offer, she may believe whatever she likes about $O$ but not so with $I$ which was a mere meter away - even if $I$ was some small event which would be practically impossible for her to discern. This is subject to the same worries about personal habit and social norms as fideism applied to cases of maximal scope, but perhaps she can will her belief about $O$ while reminding herself that she only has this freedom because of relativity, without being less apt to notice errors in reasoning about $I$, and without harming the social order. Insofar as she can do that, however, she is encouraged to treat relativity as an inevitable and immutable constraint on possibility. If she seriously allowed for the possibility that it might be false, she would treat $O$ as of a kind with $I$, both as events that she could not discern. Thus, fideist treatment of a particular claim about $O$ would undercut her ability to be a fallibilist about the background theories that specify the relevant sense of natural possibility. Since she only needs to protect her willful judgment about $O$, she could allow for theory changes that would further constrain (rather than expand) the relevant sense of possibility. Since responsible change in theory may as easily open 
new possibilities as close them, however, this half-hearted fallibilism offers little comfort.

The fideist approach may be applied to cases of still narrower scope, but the problems only increase. Further problems arise and - for a theory choice underdetermined only with a scope so narrow that it excludes recognized, practical possibilities - agnosticism clearly wins out. Imagine, as an example of such a case, the question of whether there are serious side effects associated with an exotic drug. A large-scale, clinical trial would resolve the question, but it is underdetermined with a scope that includes only circumstances where the trial has not been performed. ${ }^{5}$ If we have not performed the trial, we are not in a position to say whether the drug has side effects. Yet it would be perverse to decide that it does have side effects if we merely find the drug distasteful. Here the fideist intuition has no sway. More generally, it would be perverse to will to believe regarding a matter that would be open to investigation if only we would will to investigate. The fideist suggestion was to substitute the standard 'Believe what you will' for the usual standard in some special cases, but invoking that standard in cases that might be resolved by ordinary investigation is - in effect - to insist that it should be the usual standard.

\section{Endgame}

To summarize the action so far: There is an intuition that in cases underdetermined with maximal scope it would be permissible to believe anything, since the course of events would never force one to alter the willed belief. Such a practice may have deleterious consequences for individuals and for the community, but whether it does is an open and at least partly empirical question. The only plausible fideism regards cases of very wide scope, so underdetermination with middling and narrower scope will require a different response regardless.

\subsection{An uneasy resolution}

Since we don't know exactly how high the costs of fideism would be, we face a decision under uncertainty. We might make a leap of faith and deem the costs of fideism to be low enough, but this would be tantamount to being a fideist about the cost of fideism. The question of what fideism costs is at least partly empirical and hence is not underdetermined with maximal scope. Further enquiry could tell us more about it.

As I've argued, fideism becomes implausible for narrow scope cases like this one. It is thus incumbent on the fideist to show either that the indirect costs of fideism are negligible, that the costs are worth paying, or (contra what I argued above) that fideism is the right response to some questions which are underdetermined only with a narrow scope. Until one of these is shown, we should be agnostic about the costs of fideism.

The agnostic gives the conservative counsel that we should apply the usual standards in all cases. The fideist pleads for a risky special standard. Until we 
know more about what might follow from unusual standards in unusual cases, prudence demands agnosticism. So there should be a modest presumption in favor of agnosticism generally. Agnosticism wins the day not with a bang, but a whimper.

\subsection{What's left of the Logical Maxim}

Peirce was serious, I think, about the Logical Maxim prohibiting us ever to say that a particular problem could not be solved to an assignable degree. He did identify agnosticism and (what I've called) fideism as our two options should we face insoluble problems, but he didn't think we should seriously entertain either. He would have viewed the discussion here as, at best, a hypothetical exercise with an impossible antecedent. So Peirce would have bristled at where modern physics has taken us. Nevertheless, I don't think that the insolubilia entailed by modern physics need have worried him too much.

Peirce's Logical Maxim would require that we say it is impossible for enquiry to face some insurmountable barrier. However, this is ambiguous. Following Peirce, we can distinguish between two senses of possibility: a subjective and an objective sense. (See [Pei98, p. 355] and also [Mey02, p. 147].) The subjective sense is an epistemic modality: $P$ is (subjectively) possible if we cannot be certain that $\sim P$. The objective sense is a real modality: $P$ is (objectively) possible if is not nomologically necessary that $\sim P$.

Let $D(E, p)$ stand for 'It is objectively possible to resolve enquiry $E$ to precision $p$.' We can understand Peirce's Logical Maxim in two ways:

$L M_{1}$ : 'For all $E, p, D(E, p)$ '

$L M_{2}$ : 'For all $E, p$, it's subjectively possible that $D(E, p)$ '

For the reasons offered above, $L M_{1}$ conflicts with contemporary physics. That is, we now think that it is nomologically impossible to resolve certain questions.

Yet we can show that $L M_{2}$ has no such conflict. We now believe a theory $T$ that entails $\sim D(E, p)$ for some $E$. That is, $T$ entails that enquiry $E$ could never be resolved. If we recognize that our belief is fallible, then we believe $T$ provisionally. Perhaps as a practical matter we might abandon active pursuit of $E$, but we should not ruthlessly prohibit speculation about it. We should expect never to settle $E$, but that expectation should never be more secure than our provisional belief in $T$.

The agnosticism that worried Peirce in the Harvard lectures is "a recommendation that a certain line of inquiry be entirely abandoned" [Pei97, p. 273, my emphasis]. As we've just seen, the agnostic response to underdetermination does not provide such a recommendation. It counsels instead that we should suspend judgment until more evidence becomes available. If our physics tells us that there will never be evidence to settle the matter, then we should not expect it to be settled. But we would only consider the matter completely closed if we think that our physics is infallible. As we've seen, treating a question as 
forever underdetermined requires treating the limitation on knowledge as eternally fixed. This, I think, is what would have worried Peirce the most- the connection between underdetermination and a dogmatism about the limits of knowledge.

If we understand Peirce's Logical Maxim as $L M_{2}$, there is a simple argument for it. Peirce advocates what Meyers calls unrestricted fallibilism, the doctrine that "no proposition can be known with certainty and hence that we may be mistaken about any proposition" [Mey02, p. 145]. We can rewrite it this way:

$U F$ : 'For all $P$, it's subjectively possible that $\sim P$ '

If we instantiate $U F$ for an arbitrary $\sim D(E, p), L M_{2}$ follows as an immediate consequence. Since we know that Peirce thought of fallibilism as a matter of methodology, this might have been the what Peirce had in mind.

If so, his example of Auguste Comte is misleading. There is no general principle that shows Comte was wrong to think it was (objectively) impossible to know the composition of the stars. Rather, his error was in deriving the impossibility from his philosophy and expecting science to abide by it. Since some limit to our knowledge is a consequence of our science, we should believe in it as much as we believe in our science. We should not think that this forever closes the matter - any more than we should think our present science will stand forever.

Perhaps Peirce would still have objected to this weak, fallibilist agnosticism. Given developments in modern physics, however, I don't see how we have any other choice. 


\section{Notes}

\footnotetext{
${ }^{1}$ This passage appears in a section that Peirce probably planned to omit from the lecture. (See Turisi's editorial note [Pei97, p. 272].) Since the section would have been a digression in the lecture, I suggest that the omission was for rhetorical reasons and not because of any second thoughts about the ideas expressed.

${ }^{2}$ This framework is developed at greater length elsewhere; e.g., [Mag03] and [Mag].

${ }^{3}$ Developing themes from Peirce, Hookway [Hoo02, ch. 10] argues that cognitive habits play a crucial rôle in enquiry.

${ }^{4}$ The entailment presumes a slightly cartooned version of relativity, but the complications are incidental to the argument here.

${ }^{5}$ Perhaps the question could be decided without a clinical trial, for instance with an epidemiological study of a population that took the drug recreationally. The scope of the underdetermination, then, must also exclude circumstances where such populations exist.
}

\section{References}

[Duh54] Pierre Duhem. The Aim and Structure of Physical Theory. Princeton University Press, [1914] 1954. Translated by Philip P. Wiener from the second edition of La Théorie Physique: Son Objet, Sa Structure (Marcel Rivière \& Cie., 1914).

[EGS77] John Earman, Clark Glymour, and John Stachel, editors. Minnesota Studies in Philosophy of Science, volume VIII. University of Minnesota Press, Minneapolis, 1977.

[Gly77] Clark Glymour. Indistinguishable space-times and the fundamental group. In Earman et al. [EGS77], pages 50-60.

[Hoo02] Christopher Hookway. Truth, Rationality, and Pragmatism: Themes from Peirce. Clarendon Press, Oxford, 2002.

[Jam48] William James. The will to believe. In Alburey Castell, editor, Essays in Pragmatism, pages 88-109. Hafner Publishing Co., New York, 1948.

[Mag] P.D. Magnus. Reckoning the shape of everything: Underdetermination and cosmotopology. Forthcoming in The British Journal for the Philosophy of Science.

[Mag03] P.D. Magnus. Underdetermination and the Claims of Science. PhD thesis, University of California, San Diego, 2003. 
[Mal77] David Malament. Observationally indistinguishable space-times. In Earman et al. [EGS77], pages 61-80.

[Mey02] Robert G. Meyers. Peirce's extension of empiricism. Transactions of the C.S. Peirce Society, 38(1/2):137-154, Winter/Spring 2002.

[Pei97] Charles Sanders Peirce. Pragmatism as a Principle and Method of Right Thinking: The 1903 Harvard Lectures on Pragmatism. State University of New York Press, Albany, [1903] 1997. Edited by Patricia Ann Turisi.

[Pei98] Charles Sanders Peirce. Issues of pragmaticism. In the Peirce Edition Project, editor, The Essential Peirce, volume 2, pages 346-359. Indiana University Press, Bloomington, 1998. Originally published 1905.

[Skl85] Lawrence Sklar. Methodological conservatism. In Philosophy \&3 Spacetime Physics, pages 23-48. University of California Press, Berkeley, 1985 .

[Sta01] P. Kyle Stanford. Refusing the devil's bargain: What kind of underdetermination should we take seriously? Philosophy of Science, 68 (Proceedings):S1-S12, September 2001.

[van02] Bas C. van Fraassen. The Empirical Stance. Yale University Press, New Haven, 2002. 